\title{
Ultrasonographic and Cytological Diagnostic Difficulties of Follicular-Variant Papillary Thyroid Carcinoma
}

\author{
Orhan Asya ${ }^{1}$ (i), Ali Yumuşakhuylu² (D), Yavuz Gündoğdu ${ }^{3}$, Cemal Aydın Gündoğmuşs ${ }^{4}$, Çağatay Oysu ${ }^{2}$ (])
}

${ }^{1}$ Malazgirt State Hospital, Department of Otorhinolaryngology, Muş, Turkey

${ }^{2}$ Marmara University Pendik Training and Research Hospital, Department of Otorhinolaryngology, İstanbul, Turkey

${ }^{3}$ izzet Baysal State Hospital, Department of Otorhinolaryngology, Bolu, Turkey

${ }^{4}$ Yüksekova State Hospital, Department of Otorhinolaryngology, Hakkari, Turkey

ORCID ID: O.A. 0000-0003-0366-3099; A.Y. 0000-0002-8421-211X; Y.G. 0000-0003-3662-829X; C.A.G. 0000-0001-8662-994X; C..0. 0000-0002-6756-8456

Citation: Asya O, Yumusakhuylu A, Gundogdu Y, Gundogmus CA, Oysu C. Ultrasonographic and cytological diagnostic difficulties of follicularvariant papillary thyroid carcinoma. Tr-ENT 2021;31(1):1-5. https://doi.org/10.26650/Tr-ENT.2021.64325

\begin{abstract}
Objective: The Nuclear properties of both follicular-variant papillary thyroid carcinoma and conventional variant of papillary thyroid carcinoma are the same, but some diagnostic difficulties exist with the follicular variant. In the present study, we aimed to define the reasons for this diagnostic difficulty and raise awareness of this problem once more.

Materials and Methods: In our study, we retrospectively reviewed the ultrasonographic findings and fine-needle aspiration biopsies of 104 patients whose histopathology had been surgically proven as being either the conventional or follicular-variant papillary thyroid carcinoma in a hospital between January 2012 and December 2018.

Results: A highly suspicious sonographic pattern occurred in $56 \%$ of the conventional type, whereas only $21 \%$ of the follicular variant resulted in a suspicious sonographic pattern. The fine-needle aspiration biopsy of the conventional papillary carcinoma was consistent with malignancy or was suspected of malignancy in $80 \%$ of the cases, whereas this percentage was $58 \%$ for the follicular variant.

Conclusion: Thus, the follicular-variant of papillary thyroid carcinoma has a higher correlation to benign sonographic features and a higher rate of false negative results via cytological examination in comparison to the conventional variant. Radiologists, pathologists, and clinicians must be aware of this situation and demonstrate care in the evaluation of nodules that appear benign.
\end{abstract}

Keywords: Papillary thyroid carcinoma, ultrasound, follicular variant, aspiration biopsy

\section{INTRODUCTION}

Papillary thyroid carcinoma (PTC), the most common malignant tumor of the thyroid, has 15 histological subtypes according to the 2017 thyroid tumor classification by the World Health Organization (1). Among these subtypes, the conventional type of PTC is the most common, followed by the follicularvariant papillary thyroid carcinoma (FVPTC). Pseudo-inclusions, grooves and a ground-glass appearance are nuclear properties of PTC. In addition to these nuclear features, the formation of the papillary structures is seen in the conventional type of PTC (2). Nuclear features are common in all PTC subtypes, and what differs among these subtypes is the predominant histological pattern, which is the papillary formation in the conventional type and not the papillary formation in other types of PTC. The follicular architectural pattern is the predominant histological pattern of FVPTC $(3,4)$.

The ultrasonographic (US) character of thyroid nodules and the cytological character of aspirated material are important for the follow-up and management of thyroid nodules. To avoid unnecessary biopsies, US criteria must be established. The US features of malignant thyroid nodules include solid hypoechoic nodules, microcalcifications, extrathyroidal extensions, irregular borders, and a nodule orientation that is taller than it is wide $(5,6)$. Although the conventional type of PTC demonstrates these malignant US findings and the diagnosis of malignant nodules and decisions regarding biopsy are easier, FVPTC

Corresponding Author: Orhan Asya E-mail: orhan4913@gmail.com

Submitted: 04.02.2021 • Accepted: 04.06.2021

This work is licensed under Creative Commons Attribution-NonCommercial 4.0 International License. 
displays relatively benign sonographic features, which is why the decision to perform a biopsy is more difficult (7). Similar to US difficulties, some cytological difficulties also occur in decision-making for FVPTC.

The diagnosis of FVPTC is difficult compared to the conventional type of PTC via a fine-needle aspiration biopsy (FNAB). This is because of the properties of FVPTC that overlap with other follicular lesions (8). Moreover, the characteristic distribution of tumoral cells in the nodule may be a reason for this, for example, the location of the nuclear features beneath tumoral capsule and the multifocal rather than diffuse presentation of the nuclear properties of FVPTC (9). Furthermore, during FNAB, the center of the nodule is usually targeted (10), which may lead to procurement of the sample from areas that show a subtle presentation of the nuclear properties (9). In this study, we compared the US features of the nodules according to the estimated risk of malignancy and the sensitivity of the FNAB for the conventional type of PTC and FVPTC.

\section{MATERIALS AND METHODS}

We retrospectively reviewed the ultrasonic findings and FNABs of 104 patients whose histopathology had been surgically proven as being either conventional PTC or FVPTC at a tertiary medical center hospital between January 2012 and December 2018. The US features of the nodules were categorized as being high suspicion, intermediate suspicion, low suspicion, very low suspicion, and benign according to the nodule's sonographic pattern and risk of malignancy, as stated in the 2015 American Thyroid Association Guidelines (11). The Bethesda system was used to classify the FNAB results to report thyroid cytopathology (12). In 5 patients, FVPTC and conventional PTC co-existed; therefore, these cases were excluded. All
66 of the patients with conventional PTC underwent a total thyroidectomy, whereas 35 patients with FVPTC underwent a total thyroidectomy, and 3 patients with FVPTC underwent a lobectomy.

Data were analyzed using the Statistical Program for Social Sciences (SPSS for IBM, 17.0). Conformity of the variables to normal distribution was examined using the KolmogorovSmirnov test and histogram graphics. The mean, standard deviation, and median values were used while presenting descriptive analyses. Categorical variables were compared using the Pearson Chi-Square Test. The Mann Whitney U Test was used to evaluate nonparametric variables between two groups. The effect of FNAB and sonographic findings on the groups were examined using binary logistic regression analysis. The level of significance was accepted as $p<0.005$ for all analyses.

The study was approved by a tertiary medical center hospital Ethics Committee for Clinical Research on May 5, 2017, with numbered 09.2017.371. Informed consent was not obtained from patients because of the retrospective design of the study.

\section{RESULTS}

One hundred and four patients were included in the study. Among the patients, 70 (67.3\%) were female, and 34 (32.7\%) were male. The average age of the patients was 42.7 years. Whereas 66 (63.5\%) patients had a conventional PTC pathology, $38(36.5 \%)$ patients had an FVPTC pathology. There was no significant difference between groups in terms of age and gender as shown in Table 1.

Table 1: Comparison of Sonographic Features and Cytologic Results Between Conventional PTCs and FVPTCs

\begin{tabular}{|c|c|c|c|c|c|c|}
\hline & & \multicolumn{2}{|c|}{ Conventionel PTC $(n=66)$} & \multicolumn{2}{|c|}{ FVPTC (n=38) } & \multirow{2}{*}{$p^{1}$} \\
\hline & & $\mathbf{n}$ & $\%$ & $\mathbf{n}$ & $\%$ & \\
\hline Age & & $42 \pm 15$ & 42 & $44 \pm 15$ & 45 & $0.468^{2}$ \\
\hline \multirow{2}{*}{ Sex } & male & 23 & (35) & 11 & (29) & \multirow{2}{*}{0.537} \\
\hline & female & 43 & $(65)$ & 27 & (71) & \\
\hline \multirow{3}{*}{ ATA sonographic risk } & Low risk & 7 & (11) & 11 & (29) & \multirow{3}{*}{0.001} \\
\hline & İntermediate risk & 22 & (33) & 19 & (50) & \\
\hline & High risk & 37 & $(56)$ & 8 & (21) & \\
\hline \multirow{6}{*}{ FNAB result } & Bethesda 1 & 1 & (1.5) & 0 & $(0.0)$ & \multirow{6}{*}{0.037} \\
\hline & Bethesda 2 & 7 & (11) & 8 & (21) & \\
\hline & Bethesda 3 & 3 & $(4.5)$ & 2 & (5) & \\
\hline & Bethesda 4 & 2 & (3) & 6 & (16) & \\
\hline & Bethesda 5 & 6 & (9) & 6 & (16) & \\
\hline & Bethesda 6 & 47 & (71) & 16 & (42) & \\
\hline \multirow{2}{*}{ FNAB result } & Bethesda 1, 2, 3 or 4 & 13 & (20) & 16 & (42) & \multirow{2}{*}{0.014} \\
\hline & Bethesda 5 or 6 & 53 & (80) & 22 & (58) & \\
\hline
\end{tabular}

${ }^{1}$ Chi-Square Test, ${ }^{2}$ Mann Whitney U Test, ATA: American Thyroid Association, FNAB: Fine Needle Aspiration Biopsy 
Table 2: Correlation Between Sonographic Risk of the Thyroid Nodule and Conventional PTC

\begin{tabular}{|c|c|c|c|c|c|c|}
\hline & \multirow{2}{*}{$\beta$ estimate } & \multirow{2}{*}{ Standard error } & \multirow{2}{*}{$P$ value } & \multirow{2}{*}{ Exp(B) Odds ratio } & \multicolumn{2}{|c|}{$95 \%$ Confidence Interval for $\operatorname{EXP}(B)$} \\
\hline & & & & & Lower & Upper \\
\hline Low risk nodule & & & 0.002 & & & \\
\hline İntermediate risk nodule & 0.599 & 0.576 & 0.299 & 1.820 & 0.588 & 5.627 \\
\hline High risk nodule & 1.983 & 0.621 & 0.001 & 7.268 & 2.151 & 24.553 \\
\hline
\end{tabular}

Binary Logistic Regression

Table 3: Correlation Between FNAB and Conventional PTC

\begin{tabular}{|c|c|c|c|c|c|c|}
\hline & \multirow{2}{*}{$\beta$ estimate } & \multirow{2}{*}{ Standard error } & \multirow{2}{*}{ P value } & \multirow{2}{*}{ Exp(B) Odds ratio } & \multicolumn{2}{|c|}{ 95\% Confidence Interval for $\operatorname{EXP}(B)$} \\
\hline & & & & & Lower & Upper \\
\hline FNAB result (Bethesda 5 ve 6) & 1.087 & 0.451 & 0.016 & 2.965 & 1.224 & 7.182 \\
\hline Constant & -0.208 & 0.373 & 0.578 & 0.812 & & \\
\hline
\end{tabular}

Binary Logistic Regression

Patients with conventional PTC were grouped according to their sonographic features: 37 (56\%) were categorized as high suspicion, 22 (33.3\%) as intermediate suspicion, and 7 (10.7\%) as low suspicion as shown in Table 1 . None of the patients with conventional PTC showed a very low or benign sonographic pattern. Patients with FVPTC were also grouped according to their sonographic features: 8 (21\%) were categorized as high suspicion, 19 (50\%) as intermediate suspicion, and 11 (29\%) as low suspicion as shown in Table 1 . None of the patients with FVPTC had very low or benign sonographic patterns. While high-risk nodules were detected in $56 \%$ of the conventional variant cases, this was present in $21 \%$ of the follicular-variant cases $(p=0.001)$.

The FNAB results of patients with conventional PTC were evaluated: 47 (71.2\%) had Bethesda 6 cytology, 6 (9.1\%) had Bethesda 5 cytology, 2 (3\%) had Bethesda 4 cytology, 3 (4.5\%) had Bethesda 3 cytology, 7 (10.7\%) had Bethesda 2 cytology, and 1 (1.5\%) had Bethesda 1 cytology as shown in Table 1 . The FNAB results of the patients with FVPTC were also evaluated: 16 (42.1\%) had Bethesda 6 cytology, 6 (15.8\%) had Bethesda 5 cytology, 6 (15.8\%) had Bethesda 4 cytology, 2 (5.3\%) had Bethesda 3 cytology, 8 (21\%) had Bethesda 2 cytology, and none had Bethesda 1 cytology as shown in Table 1. In 80\% of the conventional PTC cases, malignancy or the suspicion of malignancy was detected by the FNAB, whereas this rate was $58 \%$ for FVPTC cases $(p=0.014)$.

It is known that the follicular architectural pattern is the predominant histological pattern of FVPTC, and we analyzed whether or not this could affect the FNAB result. While Bethesda 4 (follicular neoplasm or suspicious for follicular neoplasm) cytology was reported in $3 \%$ of FNAB of conventional PTC cases, this rate was approximately $16 \%$ in the follicular variant $(p=0.037)$.
Logistic regression analysis was performed to show the effect of risk factors on PTC. We found that high risk nodules increases the possibility of conventional variant papillary thyroid carcinoma by 7,268 times compared to low risk nodules as shown in Table 2 ( $p=0.00195 \%$ confidence interval). We also found that nodules with Bethesda 5 or 6 cytology increases the possibility of conventional variant papillary thyroid carcinoma by 2,965 times compared to nodules with Bethesda 1,2,3 or 4 cytology as shown in Table 3 ( $p=0.01695 \%$ confidence interval).

\section{DISCUSSION}

In our study, FVPTC clearly differs from conventional PTC when comparing the sonographic patterns of the nodules and the FNAB results. More than half of the patients with conventional PTC had border irregularity, microcalcification, or a taller-thanwide shape with a hypoechoic solid nodule, which places them in a high-risk category. However, only $21 \%$ of those with FVPTC had such a sonographic pattern. The relative paucity of border irregularity, microcalcification, or a taller-than-wide shape that we observed in FVPTC may be attributed to the propensity of these lesions to grow parallel to the normal tissue plane rather than infiltratively across the normal tissue $(5,7,13)$. Nearly onethird of the patients with FVPTC in our study had hyperechoic or isoechoic solid nodules without any other suspicious patterns, just like the nodules with multinodular goiter. This percentage was about $10 \%$ of the patients with conventional PTC in our study. The relatively frequent hyperechogenicity or isoechogenicity in FVPTC compared to conventional PTC might be related to the abundance of follicles and the lesser degree of cellularity in FVPTC (14). Hypoechogenicity of the nodule, which suggests a malignant finding, was thought to be due to the high cellularity of the nodule. The follicular neoplasms contain multiple follicular structures and less cellularity compared to conventional PTC. From this point, via US, they resemble a multinodular goiter (14). 
In contrast to the high incidence of suspicious nodules via sonograph for malignancy in conventional PTC, a lower incidence of suspicious nodules occurs in FVPTC. From this perspective, the absence of suspicious malignant features via a sonograph cannot guarantee that the thyroid nodules are benign $(13,15)$. The tumoral nodules of FVPTC are usually iso- or hyperechoic, noncalcified, round (width greater than anteroposterior dimension) nodules with regular borders (15).

The FNABs of the patients were analyzed retrospectively. Benign cytological findings (Bethesda 2) were obtained in 7 cases of the 66 conventional PTCs. From these 7 cases, in 4 cases, the biopsies were taken from a dominant nodule, and incidental micropapillary carcinoma was detected in another nodule in the thyroidectomy specimen. Thus, only $4.8 \%$ (3 out of 62 ) of patients with Bethesda 2 cytology were found to have a final pathology of conventional PTC. Similarly, there were 8 cases of Bethesda 2 cytology out of the 38 FVPTC patients, and of these, 2 cases had micropapillary carcinoma in a nodule other than the nodule that was aspirated for cytopathologic examination. Therefore, although the biopsy was taken from a pathological nodule, $16.7 \%$ (6 out of 36) of FVPTC patients showed preoperative Bethesda 2 cytology. Among the pathological nodules where a biopsy was taken, in $85.5 \%$ (53 out of 62 ) of conventional PTC cases, a preoperative cytological examination resulted in Bethesda 5 or 6 , whereas this percentage was $61.1 \%$ (22 out of 36 ) for the FVPTC cases.

Kim et al. (15) reported that the diagnosis of Bethesda 3 in FVPTC was higher than that in conventional PTC (46\% vs 19\%). In our study, this percentage was $5.3 \%$ vs $4.5 \%$, respectively, whereas an important difference exists in the Bethesda 4 category. Among all cases of FVPTC, $15.8 \%$ were reported as Bethesda 4, whereas about 3\% were reported for conventional PTCs. Kim et al. (15) reported that only 1 of the 35 FVPTC cases was diagnosed as FVPTC. In our study, no case was reported as FVPTC based on the FNAB.

The FNAB is highly sensitive in the diagnosis of PTC (16). Although the diagnosis of conventional PTC is not problematic in most cases, difficulties exist with the cytological diagnosis of FVPTC in a substantial number of cases. The presence of follicular architecture along with nuclear properties of papillary carcinoma allows us to make the cytological diagnosis of FVPTC (4). Two main reasons exist for diagnostic difficulties with FVPTC upon a cytological examination. First, FVPTC has cytomorphological properties that overlap with follicular lesions due to the presence of abundant colloid and monolayer sheets of follicular cells (17). Second, FVPTC contains very few of the nuclear properties that are characteristic of papillary carcinoma. For this reason, these nuclear properties are often missed on examination (9).

Moreover, these sparse nuclear changes may be subcapsularly located (9), which creates an interesting problem because the center of the nodule is usually targeted (18). These factors contribute to the false negative results of FVPTC using FNABs. Therefore, FNABs may be misdiagnosed as an adenomatous nodule or follicular neoplasia. These problems may lead to wrong decisions in the decision-making process. Because nearly $16 \%$ of our cases with FVPTC had follicular neoplasia on an FNAB and nearly $16 \%$ showed benign cytology on an FNAB, a more careful evaluation of nodules that appear benign is considered mandatory.

In the case of a highly suspicious nodule via a sonograph, although a cytological examination is inconsistent with malignancy or suspicion for malignancy, we usually repeat the FNAB within a short period of time. In doing so, we aim to avoid missing the patients at risk. However, this is not the case for benign nodules. To overcome this problem, during an FNAB of the nodules that appear more benign, the number of aspirations may be more than usual. A careful examination of the entire nodule must be done together with the central part, and the subcapsular location of the nodule may be aspirated in case of suspicion.

\section{CONCLUSION}

In conclusion, some difficulties exist regarding the diagnosis of FVPTC based on both sonographic and cytological examinations. The FVPTC showed a higher correlation with benign sonographic features and a higher rate of false negative results based on a cytological examination. Radiologists, pathologists, and clinicians must be aware of this difficulty and demonstrate care in the evaluation of nodules that appear benign.

Ethics Committee Approval: The study was approved by a tertiary medical center hospital Ethics Committee for Clinical Research on May 5, 2017, with numbered 09.2017.371. Informed consent was not obtained from patients because of the retrospective design of the study.

Peer Review: Externally peer-reviewed.

Author Contributions: Conception/Design of Study- O.A., A.C.Y., Y.G., C.A.G., C..O.; Data Acquisition- O.A., Y.G.; Data Analysis/InterpretationO.A., A.C.Y., Y.G., C.A.G., Ç.O.; Drafting Manuscript- O.A., A.C.Y., Ç.O.; Critical Revision of Manuscript- O.A., A.C.Y., Y.G., C.A.G., Ç.O.; Final Approval and Accountability- O.A., A.C.Y., Y.G., C.A.G., Ç.O.

Conflict of Interest: Authors declared no conflict of interest.

Financial Disclosure: Authors declared no financial support.

\section{REFERENCES}

1. Lloyd RV, Osamura RY, Klöppel G, Rosai J, Bosman FT, Jaffe ES, et al. WHO classification of tumours of endocrine organs: International Agency for Research on Cancer; 2017.

2. Rosai J, Carcangiu M, Delellis R. Tumors of the thyroid gland In: Rosai J, Sobin LH (eds) Atlas of Tumor Pathology, vol. 5. Armed Forces Institute of Pathology, New York. 1992:161-82.

3. Tielens ET, Sherman SI, Hruban RH, Ladenson PW. Follicular variant of papillary thyroid carcinoma. A clinicopathologic study. Cancer 1994;73(2):424-31. 
4. Mesonero CE, Jugle JE, Wilbur DC, Nayar R. Fine-needle aspiration of the macrofollicular and microfollicular subtypes of the follicular variant of papillary carcinoma of the thyroid. Cancer Cytopathology: Interdisciplinary International Journal of the American Cancer Society 1998;84(4):235-44.

5. Frates MC, Benson CB, Charboneau JW, Cibas ES, Clark OH, Coleman $B G$, et al. Management of thyroid nodules detected at US: Society of Radiologists in Ultrasound consensus conference statement. Radiology 2005;237(3):794-800.

6. Frates MC, Benson CB, Doubilet PM, Cibas ES, Marqusee E. Can color Doppler sonography aid in the prediction of malignancy of thyroid nodules? Journal of Ultrasound in Medicine 2003;22(2):127-31.

7. Yoon JH, Kim E-K, Hong SW, Kwak JY, Kim MJ. Sonographic features of the follicular variant of papillary thyroid carcinoma. Journal of Ultrasound in Medicine 2008;27(10):1431-7.

8. Martínez-Parra D, Fernández JC, Hierro-Guilmain CC, Pérez JS, Pérez-Guillermo M. Follicular variant of papillary carcinoma of the thyroid: to what extent is fine-needle aspiration reliable? Diagnostic Cytopathology 1996;15(1):12-6.

9. Baloch ZW, Gupta PK, Yu GH, Sack MJ, LiVolsi VA. Follicular variant of papillary carcinoma: cytologic and histologic correlation. American Journal of Clinical Pathology 1999;111(2):216-22.

10. Kini SR. Guids to Clinical Aspiration Biopsy. Thyroid. 1996.

11. Haugen BR, Alexander EK, Bible KC, Doherty GM, Mandel SJ, Nikiforov YE, et al. 2015 American Thyroid Association management guidelines for adult patients with thyroid nodules and differentiated thyroid cancer: the American Thyroid Association guidelines task force on thyroid nodules and differentiated thyroid cancer. Thyroid 2016;26(1):1-133.
12. Cibas ES, Ali SZ. The Bethesda system for reporting thyroid cytopathology. Thyroid 2009;19(11):1159-65.

13. Moon W-J, Jung SL, Lee JH, Na DG, Baek J-H, Lee YH, et al. Benign and malignant thyroid nodules: US differentiation-multicenter retrospective study. Radiology 2008;247(3):762-70.

14. Jeh S-k, Jung SL, Kim BS, Lee YS. Evaluating the degree of conformity of papillary carcinoma and follicular carcinoma to the reported ultrasonographic findings of malignant thyroid tumor. Korean Journal of Radiology 2007;8(3):192-7.

15. Kim DS, Kim J-h, Na DG, Park S-H, Kim E, Chang K-H, et al. Sonographic features of follicular variant papillary thyroid carcinomas in comparison with conventional papillary thyroid carcinomas. Journal of Ultrasound in Medicine 2009;28(12):168592.

16. Caraway NP, Sneige N, Samaan NA. Diagnostic pitfalls in thyroid fine-needle aspiration: a review of 394 cases. Diagnostic Cytopathology 1993;9(3):345-50.

17. BALOCH ZW, SACK MJ, YU GH, LIVOLSI VA, GUPTA PK. Fineneedle aspiration of thyroid: an institutional experience. Thyroid 1998;8(7):565-9.

18. Silverman JF, West RL, Larkin EW, Park HK, Finley JL, Swanson MS, et al. The role of fine-needle aspiration biopsy in the rapid diagnosis and management of thyroid neoplasm. Cancer 1986;57(6):116470. 